Seção Temática: Balanço do Fundeb

Volume 10 - 2020|n. 29

\title{
O Direito à Educação do Campo no estado do Piauí no contexto do FUNDEB
}

\author{
Jullyane Frazão Santana \\ Faculdade do Baixo Parnaíba (FAP), Chapadinha/MA - Brasil \\ Lucineide Barros Medeiros \\ Universidade Estadual do Piauí (UESPI), Teresina/PI - Brasil \\ Marli Clementino Gonçalves \\ Universidade Federal do Piauí (UFPI), Teresina/PI - Brasil
}

\section{Resumo}

O objetivo do artigo é analisar o direito à educação a partir da situação de cobertura escolar no meio rural do Piauí, no contexto da política de fundos, por meio do número de escolas e de matrículas existentes no período de 2008 a 2019, em diálogo com o financiamento realizado por meio do FUNDEB. Nesse sentido, utilizando-se dos dados referentes à quantidade de escolas e ao número de matrículas, buscou-se responder às seguintes questões: como vem se configurando a oferta da educação básica na zona rural do estado do Piauí? Em que medida a atual política de fundos tem contribuído para a materialização da Educação do Campo no estado? Há indícios de que, apesar do preceito constitucional contido nos Artigos 205 e 206 da Constituição Federal, que afirma a Educação como direito de todos, em igualdade de condições, e da política de financiamento assegurada no FUNDEB, há no Piauí o aprofundamento do processo de exclusão das populações do campo, traduzindo a violação ao direito.

Palavras-chave: Educação do Campo. FUNDEB. Piauí. Financiamento da Educação.

\section{The right to education in Piaui's rural areas taking account Fundeb's context}

\section{Abstract}

The objective of the article is to analyze the right to education based on the situation of school coverage in rural Piauí, in the context of the fund policy, through the number of schools and enrollments existing in the period from 2008 to 2019, in dialogue with the financing carried out through Fundeb. Thus, using data referring to the number of schools and the number of enrollments, we sought to answer the following questions: how has the provision of basic education in the rural area of the state of Piauí been taking shape? To what extent has the current fund policy contributed to the materialization of Countryside Education in the state? There are indications that, in spite of the constitutional precept contained in Articles 205 and 206 of the Federal Constitution that affirms Education as a right of all, under equal conditions, and the funding policy ensured by Fundeb, in Piauí there is a deepening of the process of exclusion of countryside populations, translating the violation of the right.

Keywords: Rural Education (countryside). Fundeb. Piauí. Education Funding. 
O Direito à Educação do Campo no estado do Piauí no contexto do FUNDEB

\section{Introdução}

Cada vez mais se torna inegável a importância da educação para a produção e reprodução societária. Seja em tempos de aparente normalidade ou de crises explícitas, a educação comparece como uma necessidade. Porém, além de uma construção necessária, é também um direito estabelecido nos marcos normativos do País, em consonância com acordos e orientações internacionais, a exemplo da Declaração Universal dos Direitos Humanos (DUDH), proclamada em 1948, na qual está registrado em seu Artigo XXVI que:

1. Todo ser humano tem direito à instrução. A instrução será gratuita, pelo menos nos graus elementares e fundamentais. A instrução elementar será obrigatória [...].

2. A instrução será orientada no sentido do pleno desenvolvimento da personalidade humana e do fortalecimento do respeito pelos direitos humanos e pelas liberdades fundamentais [...] (UNIC, 2009, p. 12).

A declaração foi assumida pelos países-membros, e tem como um dos momentos de alta afirmação a celebração do Pacto Internacional sobre Direitos Econômicos, Sociais e Culturais (PIDESC), em vigor a partir de 1976, trazendo no Artigo 13 que:

1. Os Estados-Signatários do presente Pacto reconhecem o direito de toda pessoa à educação. Concordam em que a educação deverá visar ao pleno desenvolvimento da personalidade humana e do sentido de sua dignidade e fortalecer o respeito pelos direitos humanos e liberdades fundamentais. Concordam ainda em que a educação deverá capacitar todas as pessoas a participar efetivamente de uma sociedade livre [...] (ONU, 1996, p. 6).

O governo brasileiro, em 1992, expediu o Decreto Presidencial $n^{\circ} 591 / 1992$, em que no Artigo $1^{\circ}$ afirma que o Pacto "será executado e cumprido tão inteiramente como nele se contém" (BRASIL, 1992). Mas, antes disso, na Constituição brasileira de 1988, o direito já havia sido consagrado, no Artigo 205, atribuindo ao Estado e à família a obrigação e incentivo, e à sociedade o papel de colaboradora: "A educação, direito de todos e dever do Estado e da família, será promovida e incentivada com a colaboração da sociedade, visando ao pleno desenvolvimento da pessoa, seu preparo para o exercício da cidadania e sua qualificação para o trabalho".

Considerando que a instituição escolar é a principal agência educacional responsável pelo ensino formalmente instituído, podemos depreender que no Artigo 206 da Constituição está a orientação que deve fundamentar a sua ação, quando lista os princípios e, em primeiro lugar, afirma que o ensino será ministrado com base na "igualdade de condições para o acesso e permanência na escola" (BRASIL, 1988).

Essa determinação requer uma política de financiamento compatível e, diante disso, a mesma Constituição, no Artigo 212, fixou percentuais para a aplicação anual da receita resultante de impostos dos governos na manutenção e desenvolvimento do ensino, com prioridade para o obrigatório, visando a universalização com "garantia de padrão de qualidade e equidade" a ser estabelecido nos planos nacionais de educação (BRASIL, 1988).

Além de estabelecer metas e respectivas estratégias, o Plano Nacional de Educação (PNE), Lei 13.005/2014 (BRASIL, 2004), com vigência no período de 2014 a 2024, contém na meta 20 o objetivo de ampliar o investimento público em educação pública, para que seja atingido "no mínimo, o patamar de 7\% (sete por cento) do Produto Interno Bruto - PIB do País 
O Direito à Educação do Campo no estado do Piauí no contexto do FUNDEB

no $5^{\circ}$ (quinto) ano de vigência desta Lei e, no mínimo, o equivalente a $10 \%$ (dez por cento) do PIB ao final do decênio".

Em consequência, os entes governamentais partícipes do pacto federativo ficam obrigados a colaborar para o alcance dessa meta. No Piauí, por exemplo, no texto do Plano Estadual de Educação (PEE/PI) há referência à garantia do investimento previsto no PNE 2014-2024, em consonância com o que consta no Artigo 214 da Constituição Federal, que trata sobre as ações integradas e regime de colaboração. Assim como o que trata o Artigo 60 da Constituição Federal, Ato das Disposições Constitucionais Transitórias (ADCT), sobre os recursos do Fundo de Manutenção e Desenvolvimento da Educação Básica e de Valorização dos Profissionais da Educação (FUNDEB), e no Artigo 223 da Constituição Estadual, que define o mínimo de $30 \%$ da receita de impostos, compreendidas as transferências para manutenção e desenvolvimento do ensino, sendo $70 \%$ destes destinados ao atendimento do Ensino Fundamental (PIAUÍ, 2016).

Estamos diante de uma política de oferta de manutenção e de desenvolvimento da educação no País, que formalmente se organiza a partir do reconhecimento da educação como direito, devendo levar em consideração o princípio que assegura condição de igualdade no acesso e na permanência.

Porém, a norma constitucional, como construção social, coexiste com a situação de desigualdade que condiciona a sociedade brasileira e piauiense desde os primórdios. De modo que não é possível tratar sobre o direito à educação sem situá-lo no contexto de negações históricas que, inclusive, justificam a sua origem e significado na sociedade moderna. Este tem por base a violência estrutural instalada através do coloniasmo e da colonialidade, que, conforme teóricos latino-americanos (SANTOS; MENESES, 2010; LANDER, 2005), estão tão bem ajustadas às medidas políticas e econômicas da ordem capitalista no País.

É neste contexto que se insere a discussão que objetiva analisar o direito à educação a partir da situação de cobertura escolar no meio rural do Piauí, no âmbito da política de fundos, por meio do número de escolas e de matrículas existentes no período de 2008 a 2019, em diálogo com o financiamento realizado através do FUNDEB.

Os dados do Instituto Nacional de Estudos e Pesquisas Educacionais Anísio Teixeira (INEP) foram obtidos principalmente junto ao Laboratório de Dados Educacionais. Com isso, foram tratados analiticamente, segundo uma perspectiva dialética, que, conforme Kosik (1976), busca apreender as relações concretas e efetivas que orientam os fenômenos em estudo.

Partimos da consideração de que, apesar do preceito constitucional contido nos Artigos 205 e 206 da Constrição Federal, que afirma a educação como direito de todos, em igualdade de condições e da política de financiamento assegurada no FUNDEB, há, no Piauí, o aprofundamento do processo de exclusão das populações do campo, traduzindo a violação ao direito.

No desenvolvimento da discussão, apresenta-se, em um primeiro momento, os marcos legais e normativos relacionados à educação como direito humano, nos quais se situa a política de Educação do Campo e as demandas para o seu financiamento; em seguida, pautamos a política de fundos, com ênfase na relação entre o FUNDEB e a realidade do estado do Piauí, no período de 2008 a 2019, mediante uma análise dos dados estatísticos 
O Direito à Educação do Campo no estado do Piauí no contexto do FUNDEB

relacionados ao número de escolas e de matrículas na zona rural do estado, considerando tensões de ordem econômica e outros fatores, dentre os quais destaca-se o fechamento de escolas.

\section{Escola e Educação Básica do Campo como direito: marcos legais e luta política}

O terreno dos direitos civis, políticos e sociais, segundo Bobbio (1987), está em correlação com o Estado, que tem as prerrogativas jurídicas de assegurá-lo. Nesse sentido, discutimos a educação, que é um direito social, e o seu financiamento público, que é papel do Estado. Behring e Boschetti (2007, p. 63), baseadas tanto em Marshall (1997) quanto em Coutinho (1996), ressaltam que "[...] o Estado europeu liberal no século XIX foi pródigo no reconhecimento dos direitos civis orientados para a garantia da propriedade privada". No final do século XIX e início do século XX, na esteira da luta pela emancipação humana, incluindo a socialização da riqueza orientada por valores não capitalistas, obtiveram-se conquistas relacionadas aos direitos políticos que, apesar de importantes para a ampliação dos direitos sociais, não foram suficientes para romper com a ordem capitalista.

No Brasil, segundo as autoras, a conquista de direitos sociais tem singularidades se compararmos aos países centrais, em razão do modo de desenvolvimento das forças sociais capitalistas, marcadas pela colonização, o escravismo e o desenvolvimento desigual e combinado (BEHRING; BOSCHETTI, 2007, p. 71-80).

No ano de 1930 foi criado o Ministério da Educação e Saúde Pública, que posteriormente, em 1953, foi segmentado em duas pastas. Em 1931 foi criado também o Conselho Nacional de Educação e o Conselho Consultivo do Ensino Comercial, expressando uma dinâmica seletiva no processo de produção da política que foi formatada em constituições, leis complementares, programas, projetos, criação e extinção de organismos governamentais, elaboração de planos educacionais, dentre outras ações e dispositivos, que perpassaram diferentes governos e uma ditadura civil-militar, momento em que houve um estímulo na economia através do ingresso de capitais estrangeiros, resultando no processo de endividamento público. A maior parte dessas dívidas foi contraída pelo setor privado e, por pressões do Fundo Monetário Internacional (FMI), houve uma "crescente e impressionante socialização" da mesma: "no Brasil, $70 \%$ da dívida pública tornou-se estatal" (BEHRING; BOSCHETTI, 2007, p. 139).

Conforme a Auditoria Cidadã da Dívida (ACD, 2020), na atualidade essa dívida se movimenta de modo sistêmico, assegurando a remuneração do setor privado com recursos públicos, especialmente os bancos, via diversos mecanismos complexos e sofisticados que promovem a diminuição do potencial de financiamento da educação pública. Um elemento de destaque, influenciador na definição da política educacional na sequência ao período ditatorial dos anos 1960/70, é a vinculação de políticas educacionais aos ditames do FMI e de outros organismos de financiamento, principalmente via contratos de empréstimos.

É importante destacar que as políticas educacionais implantadas no Brasil a partir de 1930 e na sequência, além de lentas e graduais, conforme afirmado por Behring e Boschetti (2007), foram também permeadas por tensões, disputas e incidências da sociedade civil organizada comprometida com a educação pública, movimento que também incidiu no processo de desestruturação dessas políticas, iniciado na década de 1990 e intensificado com 
O Direito à Educação do Campo no estado do Piauí no contexto do FUNDEB

reformas e ajustes fiscais, inclusive na atualidade, provocando o desmonte do patrimônio público estatal e das políticas sociais, incluindo a política educacional, com privatizações de funções, antes sob a responsabilidade do Estado, e imposição de fortes restrições ao financiamento público. A Emenda Constitucional n 95/2016 é um dos mecanismos utilizados, pois coloca limite aos gastos primários da União, incluindo gastos primários nos setores sociais por 20 anos e, de acordo com a Campanha Nacional pelo Direito à Educação (TETO..., 2018), inviabiliza o cumprimento da meta 20 e tem efeito cascata sobre outras metas. Vale ressaltar que o estado do Piauí, no final do mesmo ano de 2016, também aprovou Emenda Constitucional limitando os gastos, notadamente os sociais, em um período de 10 anos.

Essas medidas de desmonte, de austeridade fiscal e orçamentária, mostram suas consequências de modo desigual, atingido mais tenazmente os setores populares e seus territórios de vida e produção. É nesse contexto que se colocam as medidas de ataque à Educação do Campo e ao seu financiamento, apesar de ser uma conquista recente ainda em processo de estruturação.

Em que pese o Brasil ter sido considerado por muito tempo um país eminentemente agrário, como afirma a professora Edla Soares (BRASIL, 2001, p. 4), a educação rural sequer foi mencionada nos textos constitucionais de 1824 e 1891. Somente nas primeiras décadas do século XX houve a introdução da educação rural no ordenamento jurídico brasileiro, incorporando, no período, um intenso debate que se processava no seio da sociedade, a respeito da importância da educação para conter o movimento migratório e elevar a produtividade no campo.

Soares (2001) ressalta que a Constituição de 1934 expressou a insatisfação dos setores do meio rural com o governo e, por isso, foi possível assegurar no Artigo 156, Parágrafo Único, que "Para realização do ensino nas zonas rurais, a União reservará, no mínimo, vinte por cento das cotas destinadas à educação no respectivo orçamento anual".

Em 1946, pelo Decreto-Lei 9.613, foi aprovada a Lei Orgânica do Ensino Agrícola, reafirmando o disposto na Constituição de 1934 quanto ao ensino nas escolas rurais. Porém, a responsabilidade pela oferta, em parte, foi delegada à iniciativa privada, repercutindo nas obrigações do Estado na promoção do direito: "[...] as empresas industriais, comerciais e agrícolas, em que trabalham mais de cem pessoas, são obrigadas a manter ensino primário gratuito para os seus servidores e para os filhos destes" (Art. 168, III).

A escola, no período, segundo Vendramini (2015), se tornou parte de uma estratégia para conter o fluxo migratório do campo para a cidade, e tinha sua qualidade instrumentalizada e comprometida, pois era voltada ao treinamento. Essa situação também se evidenciou no tocante à estrutura de funcionamento: geralmente improvisadas, pequenas, contando com equipamentos obsoletos ou reciclados, depois de serem descartados nas escolas urbanas. A esse quadro de constituição histórica de uma rede em que milhares de escolas contam com condições precárias, soma-se o fenômeno do fechamento de muitas escolas, a exemplo do que ocorre no Piauí e é relatado por Borges (2017, p. 312):

Ao todo, 377 escolas do campo, todas elas municipais, foram fechadas no estado do Piauí no ano de 2014. Destas, 23 (6,10\%) foram extintas e 354 (93,90\%) tiveram suas atividades paralisadas. Estas instituições atendiam, em 2013, a um total de 7.088 alunos regularmente matriculados e estavam distribuídas em 111 municípios distintos, ou seja, quase metade $(49,55 \%)$ dos 224 municípios nos quais o estado do Piauí é dividido. 
O Direito à Educacão do Campo no estado do Piauí no contexto do FUNDEB

A situação potencializa o abandono do campo no contexto das políticas públicas educacionais. Isso é, ao mesmo tempo, causa e consequência da realidade de pauperização e fechamento das escolas, o que incide, de modo geral, na vida, no trabalho e no desenvolvimento político e econômico no meio rural, pois:

\section{Assim como é impossível pensarmos o trabalho independente da forma social determinada em que ele se exerce, do mesmo modo não dá para pensar a educação em abstrato, sem considerar as condições que dão significado econômico e político à diversidade de formas de educação, de conteúdos e de pedagogias (GRZYBOWSKI, 1986, p. 51).}

Podemos afirmar que a qualidade da escola do meio rural está diretamente relacionada com a qualidade do trabalho, da produção e da política educacional. Assim como é nítida a situação de isolamento das escolas do meio rural, com problemas de abastecimento elétrico e de acesso à internet, falta de assistência técnica e pedagógica, professores provisórios, sem a formação adequada para as atividades que realizam, materiais didáticos precários e de baixa qualidade, falta de água tratada e de outras condições sanitárias, mobília insuficiente, inadequada e sem manutenção, falta de equipamentos básicos como computadores, impressoras, tudo isso marcado pelo baixo financiamento, ou seja, distantes da qualidade já prevista no escopo legal e normativo do País.

Verificamos que a realidade das escolas do meio rural, de seus(as) estudantes e trabalhadores(as), está cindida em relação às consequências positivas advindas do que determinam os Artigos 205 e 206 da Constituição Federal. Tais indivíduos compõem a parcela que mais sente a situação de exclusão marcante nas políticas sociais e educacionais.

De acordo com dados do Censo Escolar de 2018 (BRASIL, 2019), naquele ano existiam 181.939 escolas no Brasil, sendo $88,7 \%$ urbanas e $11,3 \%$ rurais. A Pesquisa Nacional por Amostra de Domicílios (PNAD) de 2015 (BRASIL, 2015a) indicou que 84,72\% da população brasileira residia em áreas urbanas e $15,28 \%$ em áreas rurais, sendo que, na região Nordeste, o percentual de população rural era de $27 \%$ e, no Piauí, de $33 \%$. Quanto ao analfabetismo de pessoas com 15 anos ou mais, foi estimado em $8 \%$ no Brasil, $16,2 \%$ no Nordeste e $16,6 \%$ no Piauí (BRASIL, 2015b).

Vale ressaltar que o meio urbano no Brasil equivale a $0,63 \%$ do território, no Piauí a $0,34 \%$, denotando a vastidão dos territórios rurais voltados à produção agropecuária, indispensável à soberania alimentar, e onde subsistem modos de vida singulares e componentes da riqueza cultural do País, apesar do tratamento inferiorizante que historicamente lhe é dispensado. Apesar dessa importância estratégica, vem ocorrendo quedas expressivas nas taxas populacionais do meio rural: 1970 a 2010 sua população caiu de $44 \%$ para $15,5 \%$. No Piauí, somente no período de 1991 a 2000 , a queda na taxa de crescimento acumulado foi de $13,25 \%$. Esse fenômeno tem relação direta com o tipo de tratamento mencionado, em que se destaca a falta de uma política educacional adequada às suas especificidades e que assegure condições de acesso, permanência e progressão na escolarização de seus habitantes.

Estabelecendo comparação com a realidade das escolas urbanas que, em grande parte, especialmente quando situadas nas periferias, também são precárias, observa-se que $70 \%$ das escolas da área urbana contam com esgoto encanado, nas rurais somente $5 \%$. A consequência é que $80 \%$ das escolas rurais usa fossas sépticas e, em cerca de $15 \%$, não há 
O Direito à Educação do Campo no estado do Piauí no contexto do FUNDEB

estrutura para destinar os resíduos. Enquanto $94 \%$ das escolas urbanas estão ligadas a uma rede de água, na zona rural são somente $27 \%$, as demais utilizam poços artesianos, cacimbas ou fontes naturais; além disso,14\% não dispõem de serviço de água (BRASIL, 2016).

Estudos desenvolvidos com base nos dados do Censo Escolar de 2012 revelaram que 508 escolas rurais no Brasil não tinham itens de infraestrutura como biblioteca, computador, TV, antena parabólica, videocassete, DVD, água filtrada, saneamento básico e eletricidade, a maior parte nas regiões Norte e Nordeste (TOKARNIA, 2014).

Esse quadro integra a dinâmica social que se move a partir de tensões e disputas forjadas e justificadas no desenvolvimento desigual e que leva à violação do direito. Esse é também o cenário em que se constituiu o movimento "Por uma Educação do Campo", uma articulação envolvendo organizações, instituições e pessoas a partir de uma leitura sobre a exclusão educacional no meio rural brasileiro. Como é possível verificar no "Documentosíntese do Seminário da articulação nacional por uma Educação do Campo", escrito em 1999 (ARROYO; FERNANDES, 1999, p. 72), no qual foram discutidas as iniciativas de movimentos sociais, com destaque para o Movimento dos Trabalhadores Rurais sem Terra (MST), de outras entidades da sociedade civil e de instituições educacionais para a construção de uma política de Educação do Campo, em contraposição à realidade histórica de violações.

Sua produção delineou os princípios básicos orientadores da Educação do Campo, inclusive estabelecendo diferenciação em relação ao fenômeno conhecido na História da Educação brasileira como Educação Rural, identificado como parte de uma política negligenciadora das especificidades do território e de seus habitantes, enquanto a Educação do Campo reconhece e promove tais especificidades.

Inicialmente, a Educação do Campo realizou-se por meio de ações, projetos e programas realizados com o suporte de recursos financeiros estatais, especialmente por meio do Programa Nacional de Educação na Reforma Agrária (PRONERA). Criado em 1998, vinculado a organismos responsáveis pela Reforma Agrária no contexto do governo federal e, posteriormente, assegurando a instituição de uma Política Nacional de Educação do Campo, incluindo o PRONERA, através do Decreto Presidencial $n^{\circ}$ 7.352/2010 (BRASIL, 2010), definindo responsabilidades inclusive no tocante ao financiamento da União, através do Ministério da Educação (MEC) e dos estados e municípios. No Artigo $9^{\circ}$ está escrito que o "Ministério da Educação disciplinará os requisitos e os procedimentos para apresentação, por parte dos Estados, Municípios e Distrito Federal, de demandas de apoio técnico e financeiro suplementares para atendimento educacional das populações do campo [...]".

Visando a implementação de ações articuladas para assegurar o previsto no Decreto, foi instituído, por meio de Portaria do MEC n 81/2013 (BRASIL, 2013), o Programa Nacional de Educação do Campo (PRONACAMPO), para a realização de ações nos eixos de gestão e práticas pedagógicas, formação de professores, educação de jovens e adultos, educação profissional e tecnológica e infraestrutura física e tecnológica.

Vale ressaltar que essas conquistas foram possíveis por meio dos marcos de lutas empreendidas pelos movimentos sociais do campo realizadas ao longo da história, embora com registros negligenciados. Nos anos 1990, o protagonismo foi construído pelo (MST), contexto em que foi criado o PRONERA. Porém, antes disso, as lutas da Comissão Pastoral da Terra (CPT) e as pressões exercidas desde a atuação das Ligas Camponesas e de Sindicatos de Trabalhadores Rurais no período pós-ditadura asseguraram que, seguindo os 
O Direito à Educacão do Campo no estado do Piauí no contexto do FUNDEB

princípios contidos na Constituição de 1988 e na Lei de Diretrizes e Bases da Educação Nacional (LDB 9394/96), fosse determinado no Artigo 28 que:

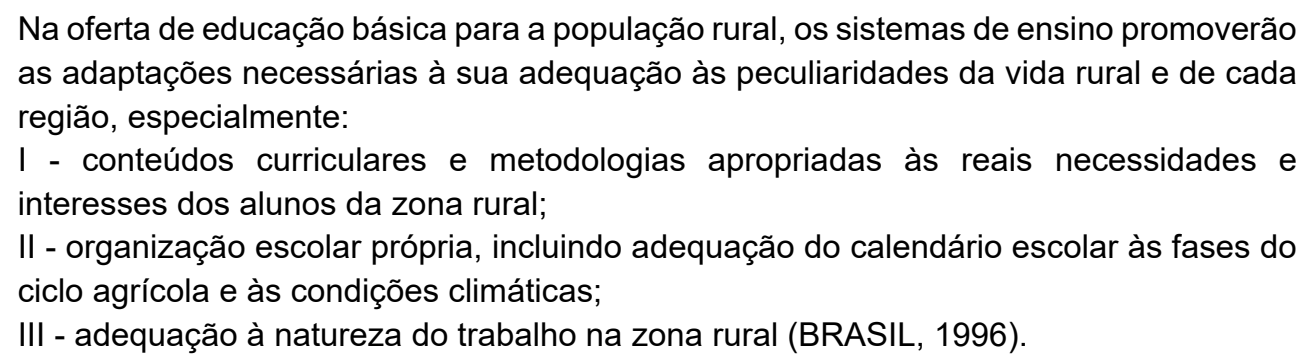

Com base na LDB, o Conselho Nacional de Educação (CNE), através de sua Câmara da Educação Básica (CEB), aprovou, em 2002, a Resolução $n^{\circ}$ 01, que instituiu as Diretrizes Operacionais para a Educação Básica nas Escolas do Campo, complementadas em 2008 através da Resolução CNE/CEB nº 03.

No ano de 2016, o Artigo 28 da LDB foi alterado pela Lei 12.960/2014 para incluir um dispositivo a ser observado em caso de fechamento de escolas:

O fechamento de escolas do campo, indígenas e quilombolas será precedido de manifestação do órgão normativo do respectivo sistema de ensino, que considerará a justificativa apresentada pela Secretaria de Educação, a análise do diagnóstico do impacto da ação e a manifestação da comunidade escolar (BRASIL, 1996).

No processo de desmonte do Estado brasileiro e da política educacional, o ônus que coube à Educação do Campo é alto: inclui extinção de organismos, como a Secretaria de Educação Continuada, Alfabetização, Diversidade e Inclusão (SECADI/MEC), criada pelo Decreto 7.690/2012, e a extinção do PRONERA, em 20 de fevereiro de 20201. Isso demonstra que, consequentemente, há também o desmonte da Educação do Campo e outras ações educacionais voltadas para o meio rural.

Tal processo aprofunda a exclusão social e educacional do território rural camponês e de seus habitantes. Processo este que não é novo, porque integra o modo de desenvolvimento capitalista, predominante na dinâmica societária, pois a sociedade capitalista é, em si mesma, excludente, constituindo-se como mecanismo para assegurar a desigualdade, sem a qual não é possível maximizar riquezas para um setor da sociedade. Boaventura Santos (2008, p. 280) ressalta que:

\section{A desigualdade e a exclusão são dois sistemas de pertença hierarquizada. No sistema de desigualdade a pertença dá-se pela integração subordinada enquanto que no sistema de exclusão a pertença dá-se pela exclusão. A desigualdade implica um sistema hierárquico de integração social.}

Por essa compreensão, quando o sistema cria políticas de inclusão, o que está promovendo são as condições de pertencimento ao próprio sistema. É por essa razão que a Educação do Campo recusa o paradigma de educação e da política educacional existente, e constrói sua luta como um novo paradigma que se expressa em uma nova política, e isso só é possível no contexto de construções insurgentes e contra-hegemônicas, por isso não pode prescindir da luta social para a sua afirmação.

\footnotetext{
1 Ver Decreto 10.252/2020.
} 
O Direito à Educação do Campo no estado do Piauí no contexto do FUNDEB

Contudo, é imperativo reconhecer que a Educação do Campo, assim como o conjunto das construções contrassistêmicas, passa por um momento de perdas. Entretanto, é também nesse processo que se encontra o gérmen do novo, pois a desigualdade e a exclusão só existem nas contradições que movem forças contrárias, e a vocação ontológica de ser mais continuará fazendo brotar lutas de transformação.

\section{O FUNDEB e a oferta da Educação do Campo no estado do Piauí}

O ano de 2020 encerra a vigência do FUNDEB como política de financiamento para a educação básica no Brasil. A política de fundos, preconizada pelos organismos internacionais como uma estratégia para a organização do Estado na perspectiva neoliberal, desenvolve-se no Brasil a partir da década de 1990, quando o país se torna signatário do modelo de gestão a partir das diretrizes neoliberais (CRUZ, 2003; PINTO, 2002). No campo educacional, a política de fundos estabeleceu percentuais mínimos a serem utilizados inicialmente no Ensino Fundamental.

O Fundo de Manutenção e Desenvolvimento do Ensino Fundamental e de Valorização do Magistério (FUNDEF), criado no Governo Fernando Henrique Cardoso, em 1997, financiava apenas o Ensino Fundamental. Sobre a lógica deste fundo, Pinto (2019, p. 27) explicita o seguinte:

A lógica da política de fundos é relativamente simples: compartilhar no âmbito de cada estado da federação e DF parte dos recursos que já são destinados por estados e municípios para a educação e distribuí-los entre as redes estaduais e municipais na proporção das matrículas das respectivas redes. É importante afirmar que recursos de um estado não são compartilhados com os outros, cabendo ao governo federal oferecer um complemento financeiro para aqueles estados e respectivos municípios em que a receita disponivel por aluno for menor, considerando as 27 unidades da federação brasileira.

O FUNDEF, seguindo a lógica descrita por Pinto (2019, p. 28), estabeleceu parâmetros de financiamento para o Ensino Fundamental, concentrando nesta etapa "cerca de $60 \%$ dos principais recursos de estados e municípios vinculados ao ensino". A restrição aos alunos do Ensino Fundamental, para fins de contabilização dos cômputos do FUNDEF, foi sendo questionada, em decorrência dos seus possíveis desdobramentos para a oferta da Educação Infantil, do Ensino Médio e da Educação de Jovens e Adultos. Dentre estes, destaca-se o "desestímulo de investimento, por parte dos poderes públicos", nas mesmas (PINTO, 2002, p. 116). Ademais, a implantação do FUNDEF provocou "uma municipalização irresponsável do ensino fundamental", a partir de 1998, constituindo-se como um dos efeitos mais drásticos e de maior impacto dessa política na configuração da oferta educacional brasileira (PINTO, 2002, p. 116).

Nesse contexto, considerando o caráter transitório do FUNDEF e o protagonismo assumido pela política de fundos no financiamento da educação nacional, em 2006, com o término de sua vigência, foi sancionada a criação do FUNDEB, através da Emenda Constitucional $n^{\circ} 53 / 2006$, regulamentada pela Lei $n^{\circ} 11.494 / 2007$, tratando-se, igualmente, de um fundo estadual de natureza contábil, em que percentuais de impostos foram constitucionalmente vinculados. Em comparação com a política de fundos anterior, houve uma "[...] ampliação da cesta de impostos abrangidos pelo novo fundo, além de deixar mais explícita a regra da complementação do governo federal ao Fundeb" (PINTO, 2019, p. 28). 
O Direito à Educação do Campo no estado do Piauí no contexto do FUNDEB

Dessa forma, além do Ensino Fundamental, o FUNDEB possibilitava as condições básicas para a oferta da Educação Infantil, do Ensino Médio e da Educação de Jovens e Adultos.

Os fatores de ponderação do FUNDEB apresentam variações entre o meio urbano e o rural. No entanto, no que concerne a esses fatores, é válido pontuar que os mesmos são estabelecidos de acordo com "a disponibilidade orçamentária imposta pelo ajuste fiscal", e não a partir dos referenciais estabelecidos para a garantia de um ensino com qualidade (CARREIRA; PINTO, 2006, p. 06).

No que tange às questões relacionadas com a Educação do Campo, Pinto (2012, p. 376) problematiza que a oferta educacional no meio rural tem se desdobrado em um contexto dramático, perpassado "por uma conjunção negativa de fatores". Segundo o autor, a maioria dessas escolas estão localizadas nas regiões mais pobres do País, ficando sob a administração das redes municipais de ensino e concentrando um número relativamente baixo de alunos matriculados. Esse fator, em conformidade com a lógica instituída pela política de fundos, caracteriza um "prejuízo" para o poder público, o que pode resultar na multisseriação das turmas e no fechamento das escolas (PINTO, 2012).

Em vista do exposto, são levantadas as seguintes questões: como vem se configurando a oferta da educação básica na zona rural do estado do Piauí? Em que medida a atual política de fundos tem contribuído para a materialização da Educação do Campo no referido estado?

Analisar as implicações da atual política de fundos para a oferta da Educação do Campo no Piauí demanda uma breve contextualização em torno de suas características socioeconômicas, considerando o fato de o estado ter recebido a complementação da União na maior parte do período de vigência do FUNDEF e em todos os anos de vigência do FUNDEB. Conforme explicitado por Sales e Silva (2013, p. 1290), o Piauí, "[...] por possuir pequena atividade econômica, arrecadava (e continua arrecadando) um volume pequeno de impostos, consequentemente contribuía muito pouco para o FUNDEF, e vem contribuindo, ainda, muito pouco para o FUNDEB", o que impacta quantitativa e qualitativamente a garantia do direto à educação no estado.

As informações disponibilizadas pela Superintendência de Pesquisas Econômicas e Sociais do Piauí (CEPRO) demostram que em 2013 o Piauí tinha uma população de 3.118.360 habitantes, distribuída em 224 municípios, dos quais $199(88,8 \%)$ tinham uma população de até 20.000 habitantes, $20(9,0 \%)$ de até 50.000 e apenas cinco $(2,2 \%)$ tinham uma população superior a 50.000 habitantes. Nesse sentido, considerando que, em média, " $89 \%$ dos municípios brasileiros - aqueles com população de até 50 mil habitantes - a receita própria representa somente 15,5\% da receita total" (PINTO, 2014, p. 629), estima-se que, no caso do Piauí, apenas $2,2 \%$ dos seus municípios teriam capacidade de financiamento das políticas sociais sob sua responsabilidade, dentre as quais destaca-se a educacional.

Ao analisar as questões que envolvem a arrecadação municipal, Pochmann e Guerra (2019) observaram que, no ano de 2016, 70\% (158) dos 224 municípios do Piauí apresentavam uma alta dependência orçamentária da União e do estado. Além do mais, em seus estudos, os autores destacaram que, aproximadamente, $40 \%$ (99) do total de municípios tinha uma baixa capacidade de investimento, possuindo "despesas de capital abaixo da média estadual de 7,2\%" (POCHMANN; GUERRA, 2019, p. 126). É válido pontuar que, segundo os autores, "53 municípios não tinham registros na base de dados do tesouro nacional acessada em 10/03/2019". 
O Direito à Educação do Campo no estado do Piauí no contexto do FUNDEB

Outro aspecto importante a ser considerado, no que concerne ao quadro situacional dos municípios piauienses, é o fato de que cerca de $84,8 \%$ destes serem considerados rurais. Ademais, importa pontuar que, no referido estado, existe uma grande concentração da distribuição do PIB, sendo que, "em 2016, os municípios $10 \%$ mais ricos concentravam $73,1 \%$ das riquezas geradas, enquanto os municípios $40 \%$ mais pobres concentravam $6,1 \%$ das riquezas geradas" (POCHMANN; GUERRA, 2019, p. 119).

Apesar das informações dispostas acima, referentes, dentre outros aspectos, à capacidade de financiamento dos municípios piauienses, estudos como os de Sales e Silva (2013) demostraram que entre os anos de 1997 a 2010 houve um intenso processo de municipalização da educação no estado do Piauí. Ao analisar o movimento das matrículas tanto nas séries iniciais quanto finais do Ensino Fundamental, os autores concluíram que a municipalização "[...] não ocorreu somente nos anos iniciais do Ensino Fundamental, como era de se esperar, mas veio a configurar-se, fortemente, nos anos finais do Ensino Fundamental" (SALES; SILVA, 2013, p. 1299), demostrando a peculiaridade desse processo quando comparado aos demais estados da Federação.

No que compete ao número de alunos(as) matriculados(as) nos anos iniciais do Ensino Fundamental, Sales e Silva (2013, p. 1296) observaram uma queda no número de matrículas nas redes municipais e estaduais, podendo "estar associada ao recuo de alguns municípios em maquiar os dados do censo escolar, os quais provavelmente foram inflacionados de 1997 a 1999, a partir da divulgação das regras do FUNDEF". Com relação aos anos finais do Ensino Fundamental, destacaram os seguintes períodos: "de 1997 a 2001 (crescimento das matrículas das duas redes), de 2002 a 2005 (crescimento da rede municipal e redução da rede estadual) e de 2006 a 2010 (redução das matrículas nas duas redes)" (SALES; SILVA, 2013, p. 1296). No que se refere a este último período, destaca-se que, nas duas redes, houve uma queda entre os anos de 2006 e 2008, com uma ligeira recuperação em 2009, seguida de uma nova queda em 2010.

A redução das matrículas nas duas redes deu-se no período de transição/implementação do FUNDEB, bem como no contexto de aprovação da Emenda Constitucional $n^{\circ} 59 / 2009$, que estabelecia a ampliação da obrigatoriedade do ensino para a faixa etária de 4 a 17 anos. Nesse segmento, Pinto e Alves (2011), tomando como base os microdados da PNAD do ano de 2008, estimaram que para garantir a universalização da educação básica as redes de ensino deveriam matricular cerca de 3, 96 milhões de novos(as) educandos(as).

No que concerne a essa ampliação, os referidos autores, objetivando mensurar quem seriam os(as) novos(as) alunos(as) da educação básica, buscaram analisar as características demográficas da população estudante e não-estudante na faixa etária de 4 a 17 anos, identificando os seguintes aspectos:

A proporção de não estudantes que mora no campo supera em quase $8 \%$ a população que mora nas cidades. Isso quer dizer que quase 1,1 milhões dos novos alunos moram na zona rural, o que é um dado significativo para o planejamento das redes de ensino no que se refere às características da oferta das novas matrículas devido às especificidades da educação da população do campo (tamanho dos prédios, lotação de professores, descolamento de alunos e/ou professores etc.) (PINTO; ALVES, 2011, p. 618). 
O Direito à Educação do Campo no estado do Piauí no contexto do FUNDEB

Nesse sentido, considerando a negação histórica do direito à educação para os povos do campo e objetivando analisar como se configurou a oferta da educação básica na zona rural do estado do Piauí, entre os anos de 2008 a 2019, apresenta-se a Tabela 1 e o Gráfico 1:

\begin{tabular}{|c|ccc} 
Tabela 1 - Número de Escolas que ofertam Educação Básica no Piauí na Zona Ru \\
\begin{tabular}{|llll}
\multicolumn{4}{c}{ nas Redes de Ensino Municipal e Estadual } \\
\hline Ano
\end{tabular} & Municipal & Estadual & Total \\
\hline 2008 & 4.759 & 61 & 4.820 \\
\hline 2009 & 4.524 & 60 & 4.584 \\
\hline 2010 & 4.224 & 61 & 4.285 \\
\hline 2011 & 4.010 & 60 & 4.070 \\
\hline 2012 & 3.850 & 57 & 3.907 \\
\hline 2013 & 3.437 & 53 & 3.490 \\
\hline 2014 & 3.080 & 54 & 3.134 \\
\hline 2015 & 2.794 & 67 & 2.863 \\
\hline 2016 & 2.655 & 66 & 2.721 \\
\hline 2017 & 2.442 & 68 & 2.510 \\
\hline 2018 & 2.183 & 68 & 2.251 \\
\hline 2019 & 1.988 & 67 & 2.055 \\
\hline
\end{tabular}

Fonte: Compilado pelas autoras com base nos dados elaborados pelo Laboratório de Dados Educacionais a partir dos microdados do Censo Escolar/INEP 2007-2019.

\section{Gráfico 1 - Número de Escolas que ofertam Educação Básica na Zona Rural do Piauí nas} Redes de Ensino Municipal e Estadual (2008 - 2019)

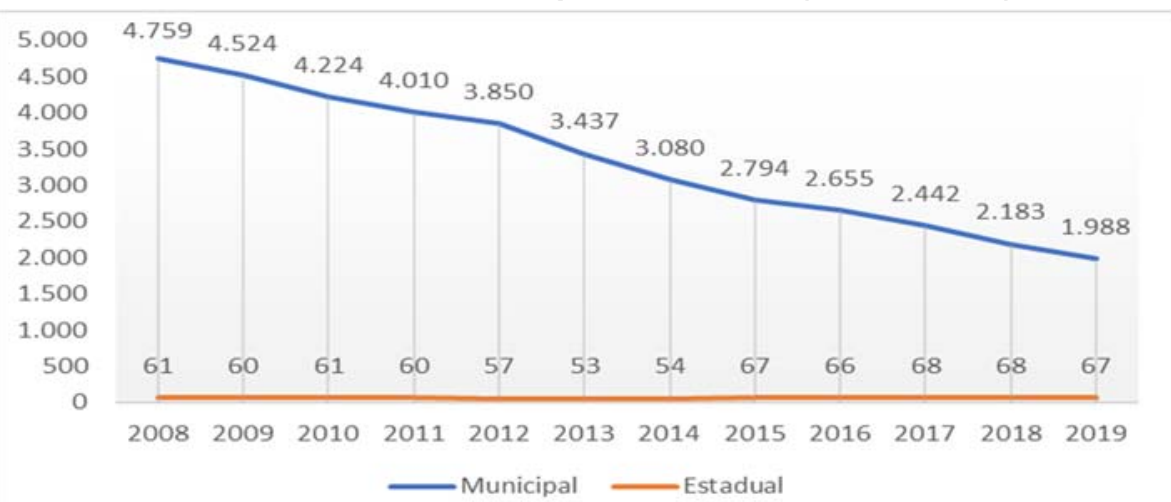

Fonte: Compilado pelas autoras com base nos dados elaborados pelo Laboratório de Dados Educacionais a partir dos microdados do Censo Escolar/INEP 2007 - 2019.

Os dados dispostos tanto na Tabela 1 quanto no Gráfico 1 demonstram a concentração do número de escolas na rede municipal e o seu movimento de fechamento, apesar da 
O Direito à Educação do Campo no estado do Piauí no contexto do FUNDEB

vigência da Lei $n^{\circ}$ 12.960/2014, que impõe condições restritivas para o fechamento de escolas.

Segundo Souza (2008), como o processo de municipalização avança mais nos anos iniciais, pois pode parecer "mais fácil" para as prefeituras assumirem a gestão dessas escolas, observa-se que a maioria das matrículas dos anos iniciais já pertencem aos municípios, enquanto nos anos finais esse número é menor. Isso significa que, muitas vezes, para concluir o Ensino Fundamental, o(a) aluno(a) tem de percorrer escolas de duas redes distintas, com diferentes padrões de gestão e avaliação, o que diminui a possibilidade de um projeto pedagógico articulado e aumenta as chances do fracasso escolar, além de outras questões que são afetadas devido a essa mudança se dar do campo para a cidade. No caso do Piauí, o processo de municipalização também avançou muito nos anos finais do Ensino Fundamental, conforme já destacado, o que sugere que os alunos da rede municipal piauiense estão menos sujeitos ao movimento de mudança de uma rede para outra durante essa etapa da educação básica.

No entanto, estudos vêm demonstrando que a concentração das escolas na rede municipal é um dos fatores que contribui para o reforço das desigualdades sociais, dado a baixa capacidade financeira dos municípios e o forte jogo político identificado nesse nível de governo. Para o autor, "[...] pela lógica da política de fundos, escolas pequenas dão 'prejuízo', pois não possuem uma escala mínima de custos" (PINTO, 2013, p. 376), o que leva os gestores a optarem pela multisseriação e/ou pelo seu fechamento pela via da nucleação e transporte dos educandos. Contudo, é necessário analisar se a racionalidade econômica contempla a dimensão do direito ao acesso e permanência ou potencializa a exclusão.

No estudo sobre o fechamento das escolas nos municípios piauienses, Borges (2017, p. 320) aponta que essa prática "denota uma política generalizada de desmonte da educação do campo", sustentando seu argumento sobre a existência de fortes correlações estatísticas entre os partidos dos prefeitos, o número de escolas fechadas e de alunos(as) afetados(as).

\begin{abstract}
Quanto mais prefeituras um partido controla, mais escolas foram fechadas pelo mesmo partido $(\rho=0,98)$. Da mesma forma, quanto mais municípios um partido controla, mais alunos foram afetados pelas políticas de gestão de cada partido $(\rho=0,97)$. Caso o fechamento de escolas do campo no estado do Piauí não fosse um fenômeno generalizado, a correlação estatística seria substancialmente mais fraca; esperar-se-ia algum grau de distorção relativo ao alinhamento político dos gestores, ou derivado da distribuição espacial heterogênea das prefeituras e, consequentemente, dos partidos que as controlam (BORGES, 2017, p. 320).
\end{abstract}

Tendo em vista a correlação apontada por Borges (2017) entre o número de escolas fechadas e o percentual de alunos(as) afetados(as), bem como a lógica de redistribuição dos recursos do FUNDEB, apresenta-se a Tabela 2 e o Gráfico 2: 
O Direito à Educação do Campo no estado do Piauí no contexto do FUNDEB

Tabela 2 - Número de Matrículas da Rede Municipal na Zona Rural por Nível de Ensino - Piauí (2008 - 2019)

\begin{tabular}{|c|c|c|c|c|c|}
\hline Ano & Pré-escola & $\begin{array}{r}\text { Séries Iniciais do } \\
\text { E.F. }\end{array}$ & $\begin{array}{r}\text { Séries Finais do } \\
\text { E.F. }\end{array}$ & Ensino Médio & Total \\
\hline 2008 & 33.048 & 147.841 & 59.247 & 1.155 & 241.291 \\
\hline 2009 & 34.022 & 139.949 & 59.297 & 1.037 & 234.305 \\
\hline 2010 & 30.973 & 128.897 & 57.318 & 605 & 217.793 \\
\hline 2011 & 31.060 & 119.439 & 56.264 & 602 & 207.365 \\
\hline 2012 & 30.517 & 110.091 & 56.519 & 442 & 197.569 \\
\hline 2013 & 30.961 & 102.539 & 55.828 & 397 & 189.725 \\
\hline 2014 & 28.817 & 97.500 & 55.349 & 68 & 181.734 \\
\hline 2015 & 27.850 & 93.496 & 53.473 & 0 & 174.819 \\
\hline 2016 & 27.156 & 88.478 & 52.213 & 0 & 167.847 \\
\hline 2017 & 26.349 & 84.718 & 51.125 & 0 & 162.192 \\
\hline 2018 & 25.001 & 78.844 & 49.374 & 0 & 153.219 \\
\hline 2019 & 24.747 & 73.476 & 46.993 & 18 & 145.234 \\
\hline
\end{tabular}

Fonte: Compilado pelas autoras com base nos dados elaborados pelo Laboratório de Dados Educacionais a partir dos microdados do Censo Escolar/INEP 2007 - 2019.

Gráfico 2 - Número de Matrículas da Rede Municipal na Zona Rural por Nível de Ensino - Piauí (2008 - 2019)

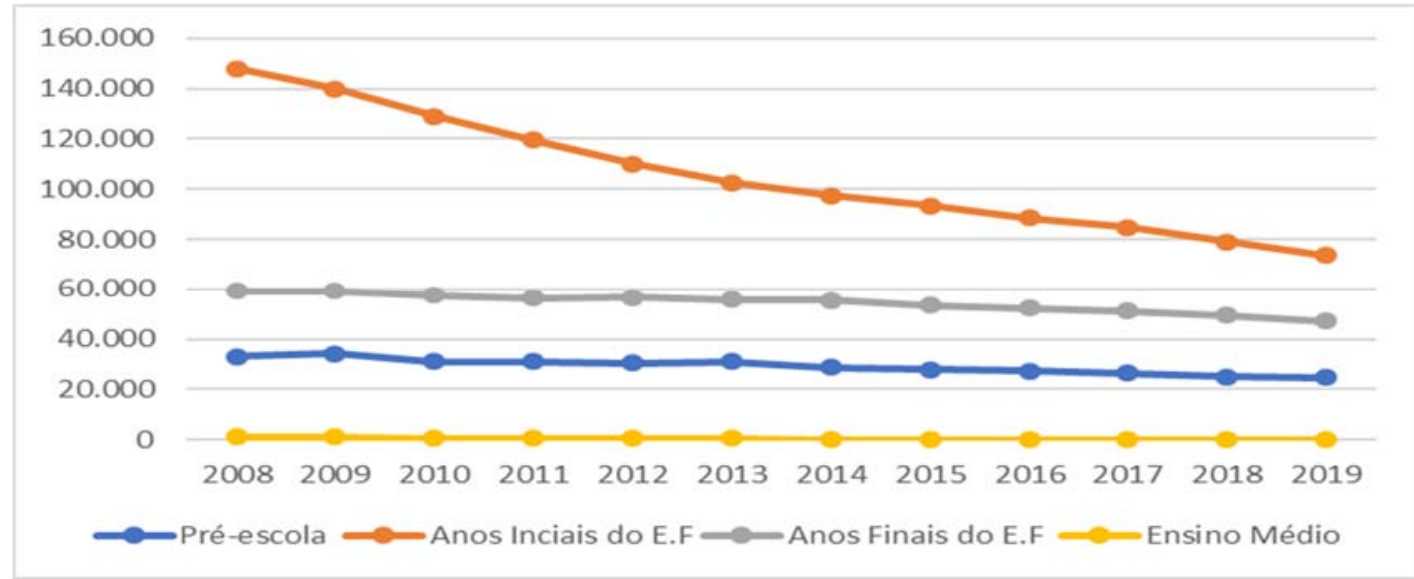

Fonte: Compilado pelas autoras com base nos dados elaborados pelo Laboratório de Dados Educacionais a partir dos microdados do Censo Escolar/INEP 2007 - 2019.

Tomando como base os dados dispostos na Tabela 2 tem-se que as matrículas da rede municipal na zona rural do Piauí tiveram uma queda de 39,9\% entre os anos de 2008 a 2019. Em um primeiro momento, esse déficit poderia ser atribuído à desresponsabilização das esferas municipais para com o Ensino Médio, visto que, "[...] considerando as áreas de atuação prioritária, os municípios receberão os recursos do FUNDEB com base no número 
O Direito à Educação do Campo no estado do Piauí no contexto do FUNDEB

de matrículas na educação infantil e no ensino fundamental" (SILVA, 2019, p. 110). Não obstante, observa-se, principalmente no Gráfico 2, que a queda de $50,3 \%$ das matrículas nas séries iniciais do Ensino Fundamental, no período em análise, protagonizou o movimento de redução das matrículas como um todo.

Observa-se, ainda, que as matrículas nos anos finais do Ensino Fundamental, no mesmo período, foram reduzidas em $20,7 \%$ e, no Ensino Médio, em 98,4\%, explicitando reduções importantes no interior de cada nível escolar e também entre os mesmos. A partir de 2013 a redução no Ensino Médio é vertiginosa. Esse quadro pede aprofundamento da análise, o que não será possível fazer neste trabalho, contudo, destacamos questões como: o padrão da oferta foi mantido apesar da queda dos números de matrícula, ou, ao contrário, as matrículas diminuíram em razão da falta de oferta, motivada, por exemplo, pelo fechamento de escolas?

É válido ressaltar que os fenômenos oferta e fechamento de escolas no meio rural estão diretamente vinculados a fatores como diminuição da população, decisões governamentais, modelos de gestão adotados e disponibilidade de recursos financeiros. Desse modo, ao considerarmos que o volume de recursos da política de fundos está diretamente relacionado com o número de matrículas, podemos inferir que os deslocamentos populacionais para o meio urbano, por razões não ligadas diretamente à educação, podem estar na base da explicação do fenômeno. A exemplo disso, tomando como base a lógica da política de fundos, indicada por Pinto (2013), bem como os alinhamentos da gestão partidária, apontados por Borges (2017), infere-se que escola no meio rural vem perdendo a importância no contexto educacional.

Quaisquer das situações, ou a combinação de todas, trazem consequências para a política de Educação do Campo, que tem como um de seus fundamentos a afirmação do campo como território de possibilidades cujo desenvolvimento implica diretamente a escolarização de sua população.

Conforme Pinto (2018, p. 862),

\begin{abstract}
Um efeito preocupante que, aparentemente, a política de fundos tem provocado é um desestímulo à incorporação de novos alunos [...]. O que se constata é a ocorrência de uma redução das matrículas no decorrer da existência dos fundos, com exceção dos anos iniciais do Fundef e na transição entre os fundos, quando novas etapas e modalidade foram incorporadas. Ao que tudo indica, ao contrário da fase inicial do Fundef, quando a maioria dos gestores desconhecia a lógica dos fundos, prefeitos e governadores têm optado por fazer o dinheiro render valendo-se da redução de matrículas.
\end{abstract}

De acordo com as questões inerentes à lógica da atual política de fundos, nota-se que a não ampliação das matrículas na zona rural dialoga diretamente com o processo de fechamento das escolas rurais, por exemplo (PINTO, 2018). Nesse sentido, compreende-se que o atual modelo de financiamento da educação no Brasil, pautado em um federalismo que descentraliza a maior parte das responsabilidades e concentra a maior parte dos recursos, não tem contribuído de forma efetiva para o fortalecimento de uma Educação do Campo de qualidade.

Corroborando essa afirmação, Torres, Silva e Moraes (2014, p. 266) destacam que os embaraços do "[...] federalismo fiscal brasileiro e a capacidade de cada governo subnacional 
O Direito à Educação do Campo no estado do Piauí no contexto do FUNDEB

são centrais e determinantes para a execução das políticas educacionais. Portanto, têm relação direta com a concepção de educação, ou seja, se do, no ou para o campo". Nesse sentido, é válido pontuar que a Educação do Campo não se resume à oferta de escolas na zona rural ou à "garantia" de acesso a uma escola urbana, constituindo-se como parte de um projeto societário de superação da ordem social vigente.

Segundo Caldart (2009, p. 40),

A Educação do campo surgiu em um determinado momento e contexto histórico e não pode ser compreendida em si mesma, ou apenas desde o mundo da educação ou desde os parâmetros teóricos da pedagogia. Ela é um movimento real de combate ao 'atual estado de coisas': movimento prático, de objetivos ou fins práticos, de ferramentas práticas, que expressa e produz concepções teóricas, críticas a determinadas visões de educação, de política de educação, de projetos de campo e de país, mas que são interpretações da realidade construídas em vista de orientar ações/lutas concretas.

Para tanto, torna-se imprescindível a garantia de um padrão de financiamento compatível com as demandas dessa modalidade, que deve reconhecer as especificidades dos povos do campo e garantir o cumprimento das leis que preveem que a educação deve ser ofertada de forma igualitária e respeitando os modos de viver e trabalhar de todo(a) e qualquer brasileiro(a) que habite nesse território.

Ao optar pelo fechamento das escolas e/ou outras opções consideradas mais viáveis economicamente, não são enfrentados os desafio de pensar uma escola do campo de qualidade, o que perpassaria a busca por soluções que mantenham "[...] o equilíbrio entre o número de alunos mínimo que garanta uma escala de funcionamento adequada e que, ao mesmo tempo, não implique, para os alunos, longas jornadas para chegar as escolas" (PINTO, 2002, p. 377), tendo como parâmetro um custo aluno qualidade inicial que dialogue mais diretamente com os desafios da oferta em municípios de pequeno porte e com baixa arrecadação própria. Ademais, um aspecto que não cabe nos limites deste trabalho, mas que deve ser enfrentado em pesquisas futuras, é o de problematização e investigação das questões referentes ao impacto do fechamento de escolas no meio rural e o quantitativo de professores formados nas Licenciaturas em Educação do Campo.

\section{Considerações Finais}

Com base na discussão teórica sobre o direito à educação e sobre as demandas que orientam a instituição e realização da Educação do Campo, e tendo em vista os dados apresentados a respeito do número de escolas e matrículas existentes na série histórica entre 2008 e 2019 no Piauí, no contexto da política de fundos, conclui-se que no cenário predomina a diminuição do número de escolas municipais e estaduais do meio rural, em face do fenômeno do baixo número de matrículas e do fechamento de escolas.

Nos marcos desta discussão não é possível afirmar qual das duas situações é determinante, se a baixa nas matrículas se deve ao fechamento de escolas, ou o contrário. Contudo, ambas compõem o contexto de negligência aos direitos do povo do campo à educação e, consequentemente, à afirmação do modo de vida camponês. Nesse sentido, torna-se necessário analisar se a racionalidade econômica contempla a dimensão do direito ao acesso e permanência ou potencializa a exclusão dos povos do campo. É válido pontuar que o FUNDEB, sozinho, não explica as situações e movimentos identificados no decorrer 
O Direito à Educacão do Campo no estado do Piauí no contexto do FUNDEB

deste estudo, sendo necessário um olhar para as questões que perpassam o pacto federativo brasileiro, bem como o lugar que a educação ofertada no meio rural foi ocupando no cenário das políticas educacionais.

O contexto apresentado neste trabalho demanda a realização de pesquisas que busquem analisar se o processo de fechamento das unidades escolares seguiu o disposto na Lei $\mathrm{n}^{\circ} 12.960 / 2014$, e quais as estratégias dos municípios para garantir o direito à educação aos estudantes matriculados, anteriormente, nas instituições, e contribuir efetivamente com a permanência das populações no território e com o seu desenvolvimento humano, socioambiental e econômico. Outras pesquisas poderiam debruçar-se, também, sobre as condições de infraestrutura e resposta da comunidade ao fechamento dessas escolas.

\section{Referências}

ACD. Auditoria Cidadã da Dívida. Sistema da Dívida e Deterioração Salarial no Brasil. Brasília, 2020. Disponível em: <https://auditoriacidada.org.br/>. Acesso em: 10 maio 2020.

ARROYO, Miguel Gonzalez; FERNANDES. Bernardo Mançano. A educação básica e o movimento social do campo. Brasilia, DF: Articulação Nacional Por uma Educação Básica do Campo, 1999.

BEHRING, Eliane Rossetti; BOSCHETTI, Ivanete. Política social: fundamentos e história. 3. ed. São Paulo: Cortez, 2007.

BOBBIO, Norberto. Estado governo sociedade: para uma teoria geral da política. 14. ed. Rio de Janeiro: Paz e Terra, 1987.

BRASIL. Constituição da República Federativa do Brasil de 1988. Diário Oficial da União, Brasília, 1988. Disponível em: <http://www.planalto.gov.br/ccivil_03/constituicao /constituicaocompilado.htm>. Acesso em: 16 jan. 2018.

BRASIL. Decreto $n^{\circ} 591$, de 6 de julho de 1992. Atos Internacionais. Pacto Internacional sobre Direitos Econômicos, Sociais e Culturais. Diário Oficial da União, Brasília, 1992. Disponível em: <http://www.planalto.gov.br/ccivil_03/decreto/1990-1994/d0591.htm>. Acesso em: 10 maio 2020.

BRASIL. Lei n 9394/1996. Lei de Diretrizes e Bases da Educação. Diário Oficial da União, Brasília, 1996. Disponível em: <https://www.planalto.gov.br/ccivil_03/Leis/L9394.htm>. Acesso em: 08 dez. 2016.

BRASIL. Ministério da Educação. Conselho Nacional de Educação. Parecer n, 36/2001. Diretrizes Operacionais para a Educação Básica nas Escolas do Campo. Diário Oficial da União, Brasília, 2002. Disponível em: <http://portal.mec.gov.br/index.php?option=com _docman\&view=download\&alias=6803-pceb036-01\&ltemid=30192>. Acesso em: 20 mar. 2020.

BRASIL. Lei 13.005/2004. Plano Nacional de Educação. Diário Oficial da União, Brasília, 2004. Disponível em: <http://pne.mec.gov.br/18-planos-subnacionais-de-educacao/543plano-nacional-de-educacao-lei-n-13-005-2014>. Acesso em: 10 maio 2020.

BRASIL. Emenda Constitucional n. 59, de 11 de novembro de 2009. Diário Oficial da União, Brasília, 2009. Disponível em: <http://www6.senado.gov.br/legislacao/ ListaPublicacoes .action? $\mathrm{id}=260049>$. Acesso em: 10 maio 20120. 
O Direito à Educação do Campo no estado do Piauí no contexto do FUNDEB

BRASIL. Decreto 7.352 de 4 de novembro de 2010. Dispõe sobre a política de educação do campo e o Programa Nacional de Educação na Reforma Agrária - PRONERA. Diário Oficial da União, Brasília, 2010. Disponível em: <http://portal.mec.gov.br/docman/marco-2012pdf/10199-8-decreto-7352-de4-de-novembro-de-2010/file>. Acesso em: 10 maio 2020.

BRASIL. Portaria $n^{\circ} 86$ de 1 de fevereiro de 2013. Institui o Programa Nacional de Educação do Campo - PRONACAMPO, e define suas diretrizes gerais. Diário Oficial da União, Brasília, 2013. Disponível em: <http://pronacampo.mec.gov.br/images/pdf/port_86_01022013.pdf>. Acesso em: 10 maio 2020.

BRASIL. Presidência da República. Lei n. ${ }^{\circ}$ 12.960, de 27 de março de 2014. Altera a Lei no 9.394, de 20 de dezembro de 1996, que estabelece as diretrizes e bases da educação nacional, para fazer constar a exigência de manifestação de órgão normativo do sistema de ensino para o fechamento de escolas do campo, indígenas e quilombolas. Diário Oficial da União, Brasília, 2014. Disponível em: <http://www.planalto.gov.br/ccivil_03/_Ato20112014/2014/Lei/L12960.htm>. Acesso em: 10 maio 2020.

BRASIL. PNAD. Pesquisa Nacional por Amostra de Domicílios. População. Brasília, 2015a. Disponível em: <https://educa.ibge.gov.br/jovens/conheca-o-brasil/populacao/18313populacao-rural-e-urbana.html>. Acesso em: 20 maio 2020.

BRASIL. PNAD. Pesquisa Nacional por Amostra de Domicílios. Síntese dos Indicadores. Brasília, 2015b. Disponível em: <https://biblioteca.ibge.gov.br/visualizacao/livros/ liv98887.pdf>. Acesso em: 20 maio 2020.

BRASIL. INEP. Instituto Nacional de Estudos e Pesquisas Educacionais Anísio Teixeira. Educacenso. Censo Escolar 2016. Brasília, 2016. Disponível em: <http://downl oad.inep.gov.br/educacao_basica/censo_escolar/notas_estatisticas/2017/notas_estatisticas_ censo_escolar_da_educacao_basica_2016.pdf>. Acesso em: 20 mar. 2020.

BRASIL. Ministério da Educação. INEP. Instituto Nacional de Estudos e Pesquisas Educacionais Anísio Teixeira. Notas estatísticas Censo Escolar 2018. Brasília, 2019. Disponível em: <http://download.inep.gov.br/educacao_basica/censo_escolar/notas_estatis ticas/2018/notas_estatisticas_censo_escolar_2018.pdf>. Acesso em: 20 maio 2020.

CALDART, Roseli Salete. Educação do campo: notas para uma análise de percurso. Trab. Educ. Saúde, v. 7, n. 1, p. 35-64, 2009.

COUTINHO, Carlos Nelson. Marxismo e política. A dualidade de poderes e outros ensaios. 2. ed. São Paulo: Cortez, 1996.

CRUZ, Rosana Evangelista da. Banco Mundial e política educacional: cooperação ou expansão dos interesses do capital internacional? Educar em Revista, Curitiba, n. 22, p. 5175, 2003.

GRZYBOWSKY, Cândido. Esboço de uma alternativa para pensar a educação no meio rural. Contexto \& Educação, São Paulo, ano 1, n. 4, p. 47-59, out./dez. 1986.

KOSIK, K. Dialética do Concreto. 2. ed. São Paulo: Paz e Terra, 1976.

LANDER, Edgardo (Org.). A colonialidade do saber: eurocentrismo e ciências sociais. Perspectivas latino-americanas, Buenos Aires, Colección Sur Sur, p. 118-142, 2005. 
O Direito à Educação do Campo no estado do Piauí no contexto do FUNDEB

MARSHALL, Thomas Humphrey. Cidadania, classe social e status. Rio de Janeiro: Zahar, 1997.

ONU. Organização das Nações Unidas Brasil. Pacto Internacional dos Direitos Econômicos, Sociais e Culturais. 1996. Disponível em: <https://www.dge.mec.pt/sites/ default/files/ECidadania/educacao_para_a_Defesa_a_Seguranca_e_a_Paz/documentos/pac to_internacional_sobre_direitos_economicos_sociais_culturais.pdf $>$. Acesso em: 10 maio 2020.

PIAUÍ. Secretaria de Estado da Educação. Plano Estadual de Educação. Teresina: Secretaria Estadual de Educação do Piauí, 2016.

PINTO, José Marcelino de Rezende. Financiamento da educação no Brasil: um balanço do governo FHC (1995-2002). Educação \& Sociedade, Campinas, v. 23, n. 80, p. 108-135, 2002.

PINTO, José Marcelino de Rezende. O potencial de controle social dos conselhos do Fundef e o que se pode esperar dos conselhos do Fundeb. In: SOUZA, Donaldo Bello de (Org.). Conselhos municipais e controle social da educação: descentralização, participação e cidadania. São Paulo: Xamã, 2008. p. 153-168.

PINTO, José Marcelino de Rezende. O Financiamento da Educação na Constituição Federal De 1988: 30 Anos de Mobilização Social. Educação \& Sociedade, Campinas, v. 39, p. 1-24, 2018.

PINTO, José Marcelino de Rezende. "A política de fundos no Brasil para o financiamento da educação e os desafios da equidade e qualidade". Propuesta Educativa, Año 28, n. 52, p. 24-40, nov. 2019.

POCHMANN, Marcio; GUERRA, Alexandre. Piauí: trajetória e transição econômica. Teresina: CEPRO, 2019. 169 p.

SALES, L. C.; SILVA, M. J. G. S. E. A Movimentação das Matrículas no Ensino Fundamental no Estado do Piauí. Educação e Realidade, Porto Alegre, v. 38, p. 1283-1301, 2013.

SANTOS, Boaventura de Sousa (Org.). Conhecimento prudente para uma vida decente: um discurso sobre ciências revisitado. São Paulo: Cortez, 2003.

SANTOS, Boaventura de Sousa. A gramática do tempo: para uma nova cultura política. 2. ed. São Paulo: Cortez, 2008.

SILVA, Samara de Oliveira. Política educacional para o ensino médio na rede estadual do Piauí: limites do atendimento e das condições de oferta para a garantia do direito à educação no contexto do FUNDEB. 2019. 315 f. Tese (Doutorado em Educação) - Faculdade de Educação, Programa de Pós-Graduação em Educação, Universidade de Campinas Campinas, 2019.

SOUZA, Donaldo Bello de (Org.). Conselhos municipais e controle social da educação: descentralização, participação e cidadania. São Paulo: Xamã, 2008.

TETO de gastos inviabiliza a implementação do plano nacional de educação. De Olho nos Planos, São Paulo, 2018. Disponível em: <http://www.deolhonosplanos.org.br/teto-degastos-inviabiliza-pne/>. Acesso em: 10 maio 2020. 
O Direito à Educação do Campo no estado do Piauí no contexto do FUNDEB

TOKARNIA, Mariana. Brasil tem 508 escolas rurais sem infraestrutura, diz estudo. EBC.

Empresa Brasil de Comunicação, Brasília, 2014. Disponível em: <https://www.ebc.com.br/educacao/2014/09/brasil-tem-508-escolas-rurais-sem-

infraestrutura-diz-estudo>. Acesso em: 29 maio 2020.

TORRES, Julio Cesar; SILVA, Claudio Rodrigues da; MORAES, Agnes lara Domingos. Escolas públicas no campo: retrospectiva e perspectivas em um contexto de projetos políticos em disputa. Revista Eletrônica de Educação, v. 8, n. 2, p. 262-272, 2014.

UNIC. Centro de Informações das Nações Unidas no Brasil. Declaração Universal dos Direito Humanos. Rio de Janeiro: UNIC, 2009. [1948]. Disponível em <https://nac oesunidas.org/wp-content/uploads/2018/10/DUDH.pdf>. Acesso em: 10 maio 2020.

VENDRAMINI, Célia Regina. Qual o futuro das escolas no campo? Educação em Revista, Belo Horizonte, v. 31, n. 3, jul./set. 2015.

Jullyane Frazão Santana é professora do curso de Pedagogia na Faculdade do Baixo Parnaíba (Fap); Mestre em Educação pela Universidade Federal do Piauí; Possui Licenciatura Plena em Pedagogia pela Universidade Federal do Piauí- Campus Ministro Reis Veloso (UFPI).

ORCID: http://orcid.org/0000-0002-4537-7085

E-mail: jullyanefrazao@hotmail.com

Lucineide Barros Medeiros é professora Adjunta, Dedicação Exclusiva, da Universidade Estadual do Piauí - UESPI. Possui Graduação em Pedagogia pela Universidade Federal do Piauí (1998), Mestrado em Educação pela Universidade Federal do Piauí (2004) e Doutorado pela Universidade do Vale do Rio dos Sinos - UNISINOS (2010); durante um semestre letivo (2009/1) esteve integrada às atividades acadêmicas do Doutorado em Educação da Universidad Pedagógica Nacional da Colômbia.

ORCID: http://orcid.org/0000-0002-1538-2705

E-mail: lucineidebarrosmedeiros@yahoo.com.br

Marli Clementino Gonçalves é graduada em Pedagogia pela Universidade Federal do Piauí (2003), Especialista em Educação do Campo e Desenvolvimento pela Universidade de Brasília (2005) e Mestre e Doutora em Educação pela Universidade Federal do Piauí. Atualmente é Professora Efetiva, Adjunto I da Universidade Federal do Piauí na área de Fundamentos Políticos e Administrativos da Educação.

ORCID: http://orcid.org/0000-0002-9802-9535

E-mail: marliclementino@yahoo.com.br 


\section{Editores do volume 10}

Márcia Aparecida Jacomini - Universidade Federal de São Paulo, Brasil

José Marcelino de Rezende Pinto - Universidade de São Paulo, Brasil

\section{Comitê Editorial}

Nalú Farenzena - Universidade Federal do Rio Grande do Sul, Brasil

Juca Gil - Universidade Federal do Rio Grande do Sul, Brasil

Theresa Adrião - Universidade Estadual de Campinas, Brasil

Ângelo Ricardo de Souza - Universidade Federal do Paraná, Brasil

\section{Conselho Editorial}

\section{Alejandro Morduchowicz}

Universidad Pedagógica, Provincia de Buenos Aires, Argentina

Andréa Barbosa Gouveia

Universidade Federal do Paraná, Brasil

Fernanda Saforcada

Universidade de Buenos Aires, Argentina

Jacques Velloso

Universidade de Brasília, Brasil

João Monlevade

Senado Federal, Brasil

Jorge Abrahão de Castro

Instituto de Pesquisa Econômica Aplicada / IPEA, Brasil

Lisete Regina Gomes Arelaro

Universidade de São Paulo, Brasil

Luis Carlos Sales

Universidade Federal do Piauí, Brasil

Luiz de Sousa Junior

Universidade Federal da Paraíba, Brasil

Luiz Fernandes Dourado

Universidade Federal de Goiás, Brasil

Magna França

Universidade Federal do Rio Grande do Norte, Brasil

Marcos Edgar Bassi

Universidade Federal de Santa Catarina, Brasil

Maria Angélica Pedra Minhoto

Universidade Federal de São Paulo, Brasil

Maria Beatriz Luce

Universidade Federal do Rio Grande do Sul, Brasil

Maria Dilnéia Espíndola Fernandes

Universidade Federal de Mato Grosso do Sul, Brasil

Nelson Cardoso do Amaral

Universidade Federal de Goiás, Brasil

Nicholas Davies

Universidade Federal Fluminense, Brasil

Robert E. Verhine

Universidade Federal da Bahia, Brasil

Romualdo Portela de Oliveira

Universidade de São Paulo, Brasil

Rosana Gemaque Rolim

Universidade Federal do Pará, Brasil

Rubens Barbosa de Camargo

Universidade de São Paulo, Brasil

Theresa Adrião

Universidade Estadual de Campinas, Brasil

Tristan McCowan

University of London, Reino Unido

Vera Jacob

Universidade Federal do Pará, Brasil

Vera Peroni

Universidade Federal do Rio Grande do Sul, Brasil

Vitor Henrique Paro

Universidade de São Paulo, Brasil

\section{Equipe editorial}

Apoio ao Comitê Editorial: Caio Cabral da Silva

Diagramação, Revisão de português e normalização: Edson Leonel de Oliveira

Revisão de inglês: Sabrina Ferreira

Fineduca - Revista de Financiamento da Educação

Associação Nacional de Pesquisa em

Financiamento da Educação

e-mail: revista.fineduca@gmail.com | site: http://seer.ufrgs.br/fineduca 